\title{
Hair follicle development and related gene and protein expression of skins in Rex rabbits during the first 8 weeks of life
}

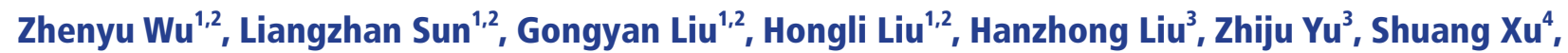 \\ Fuchang $\mathrm{Li}^{1,2, *}$, and Yinghe Qin ${ }^{4, *}$
}

\author{
* Corresponding Authors: \\ Fuchang Li \\ Tel: +86-0538-8242593-8319, Fax: +86-0538-8241419, \\ E-mail: chlf@sdau.edu.cn \\ Yinghe Qin \\ Tel: +86-010-62731022, Fax: +86-010-62731022, \\ E-mail: qinyinghe@cau.edu.cn
}

${ }^{1}$ College of Animal Science and Technology, Shandong Agricultural University, Taian, Shandong 271018,

China

2 Shandong Provincial Key Laboratory of Animal Biotechnology and Disease Control and Prevention, Shandong Agricultural University, Taian, Shandong 271018, China

${ }^{3}$ Sichuan Academy of Grassland Sciences, Chengdu, Sichuan 610091, China

${ }^{4}$ College of Animal Science and Technology, China

Agricultural University, Beijing 100193, China

ORCID

Zhenyu Wu

https://orcid.org/0000-0003-3626-1766 Liangzhan Sun

https://orcid.org/0000-0003-0670-0051

Gongyan Liu

https://orcid.org/0000-0003-1478-7759

Hongli Liu

https://orcid.org/0000-0001-6782-6534

Hanzhong Liu

https://orcid.org/0000-0003-1189-5375

Zhiju Yu

https://orcid.org/0000-0002-4102-5867

Shuang Xu

https://orcid.org/0000-0003-3901-9676

Fuchang Li

https://orcid.org/0000-0002-5670-8038

Yinghe Qin

https://orcid.org/0000-0001-6991-2284

Submitted Mar 30, 2018; Revised Jul 13, 2018; Accepted Sept 13, 2018
Objective: We aimed to observe hair follicle (HF) development in the dorsal skin and elucidate the expression patterns of genes and proteins related to skin and HF development in Rex rabbits from birth to 8 weeks of age.

Methods: Whole-skin samples were obtained from the backs of Rex rabbits at $0,2,4,6$, and 8 weeks of age, the morphological development of primary and secondary HFs was observed, and the gene transcript levels of insulin-like growth factor-I (IGF-I), epidermal growth factor $(E G F)$, bone morphogenetic protein 2 (BMP2), transforming growth factor $\beta-1,2$, and 3 (TGF $\beta$ $1, T G F \beta-2$, and $T G F \beta-3$ ) were examined using quantitative real-time polymerase chain reaction (PCR). Additionally, Wnt family member $10 \mathrm{~b}$ (Wnt 10b) and $\beta$-Catenin gene and protein expression were examined by quantitative real-time PCR and western blot, respectively.

Results: The results showed significant changes in the differentiation of primary and secondary HFs in Rex rabbits during their first 8 weeks of life. The IGF-I, EGF, TGF $\beta-2$, and TGF $\beta-3$ transcript levels in the rabbits were significantly lower at 2 weeks of age than at birth and gradually increased thereafter, while the $B M P 2$ and $T G F \beta-1$ transcript levels at 2 weeks of age were significantly higher than those at birth and gradually decreased thereafter. $\beta$-Catenin gene expression was also significantly affected by age, while the $W n t 10 b$ transcript level was not. However, the Wnt10b and $\beta$-catenin protein expression levels were the lowest at 2 and 4 weeks of age.

Conclusion: Our data showed that a series of changes in HFs in dorsal skin occurred during the first 8 weeks. Many genes, such as IGF-I, EGF, BMP2, TGF $\beta-1$, TGF $\beta-2, T G F \beta-3$, and $\beta$-Catenin, participated in this process, and the related proteins $W n t 10 b$ and $\beta$-Catenin in skin were also affected by age.

Keywords: Genes; Proteins; Skin and Hair Follicle; Development; Rex Rabbit

\section{INTRODUCTION}

Animal wool is an important economic resource, and Rex rabbits are famous for their fur and meat. For Rex rabbit production, skin quality is the most important factor. As such, many studies have attempted to identify candidate genes related to animal wool quality. Most of these efforts have focused on humans, sheep and mice. In the present study, we aimed to observe hair follicle (HF) development in the dorsal skin and describe the expression pattern of genes related to skin and HF development in Rex rabbits from birth to 8 weeks of age.

Rabbit hair is an important commercial product generated by Rex rabbits. The HF cycle can typically be divided into three phases: anagen, catagen, and telogen [1]. Similar to the Cashmere goat, the Rex rabbit has a double-coat skin, which contains two distinct types of HFs: primary and secondary HFs [2]. The HFs postnatally enter into the cycle. The HF growth cycle and obviously different sizes of primary and secondary HFs enable the easy differen- 
tiation of hair cycle phases and HF types [3].

Many genes, such as epidermal growth factor (EGF), insulin-like growth factor-I (IGF-I), bone morphogenetic protein $(B M P)$, transforming growth factor $\beta$ (TGF- $\beta)$, and Wnt, have been implicated in HF and skin development. The EGF plays an important role in the development of epithelial tissue. The administration of EGF to newborn mice delays HF development, decreases the hair growth rate and reduces hair diameter $[4,5]$. A previous study showed that the physiological levels of IGF-I maintain the in vivo rates of HF growth in vitro, and in the absence of $I G F-I$, HFs enter the catagen stage of the hair growth cycle [6]. Moreover, using semiquantitative polymerase chain reaction (PCR), Little et al [7] showed that IGF-I receptor mRNA was downregulated in rat HFs upon the onset of the catagen stage. The BMP2 has previously been shown to suppress extracellular matrix degradation by inhibiting the expression of matrix metalloproteinase-13 [8].

Members of the TGF $\beta$ family play important roles in many essential cellular processes. TGF $\beta$ - 1 has been shown to influence proliferation, differentiation, migration and apoptosis, whereas TGF $\beta$ - 2 has been implicated in animal immune processes $[8,9]$. TGF $\beta$ s are membrane-spanning proteins that can be subdivided into three types (TGF $\beta-1, T G F \beta-2$, and TGF $\beta$ 3 ) according to their structure and function. TGF $\beta-1$ and $T G F \beta$ - 2 bind to serine/threonine kinase receptors on the plasma membrane and activate Smad molecules as well as additional signaling proteins that work with Smad molecules to regulate gene expression. TGF $\beta$-3 can affect the binding of TGF $\beta$ s to other receptors [10]. TGF $\beta-1$ is expressed in nipple cells and the inner root sheath of immature mouse skin. However, TGF $\beta$ 2 and TGF $\beta-3$ are expressed in only the inner root sheath. In mature mouse skin, TGF $\beta-1, T G F \beta-2$, and TGF $\beta$ - 3 are expressed in only the inner root sheath. Thus, the TGF $\beta$ family likely plays an important role in skin maturation.

$W n t / \beta$-Catenin signaling has been implicated in the development of skin and hair as well as the related appendages in the feathers of birds [11]. Wnt family member 10b (Wnt10b) promotes hair shaft growth and epithelial differentiation [12, 13]. In the Wnt/ $\beta$-Catenin signaling pathway, $\beta$-Catenin, which can be translocated to the nucleus, accumulates in the cell plasma. In the nucleus, $\beta$-Catenin interacts with transcription factor/lymphoid enhancer-binding factor to regulate the expression of background genes [14].

In the present study, we aimed to observed HF development and describe the expression of the genes related to $\mathrm{HF}$ development in Rex rabbits from birth to 8 weeks of age.

\section{MATERIALS AND METHODS}

\section{Experimental rabbits and sample collection}

All study procedures were approved by the Shandong Agricultural University Animal Care and Use Committee in accordance with the Guidelines for Experimental Animals established by the Ministry of Science and Technology (Beijing, China). During the trial, the rabbits were housed in a closed and ventilated building at a maximum temperature of $22^{\circ} \mathrm{C}$, a minimum temperature of $15^{\circ} \mathrm{C}$ and a $50 \%$ to $60 \%$ relative humidity. A $12-\mathrm{h}$ light (6:30 to 18:30) cycle was used. The diets were formulated according to rabbit requirements by using the same formula as De Blas and Wiseman [15]. The feed was pressed into 4-mm pellets using a pellet mill.

Newborn rabbits were 0 weeks old, and whole-skin samples were obtained from the backs of the rabbits at $0,2,4,6$, and 8 weeks ( 6 rabbits per stage and equal ratios for males and females). Two skin samples $\left(1 \mathrm{~cm}^{2}\right)$ were collected from the mid-back, and one sample was immediately frozen in liquid nitrogen, transported to the laboratory and stored at $-80^{\circ} \mathrm{C}$. The other sample was fixed in 4\% paraformaldehyde overnight.

\section{RNA extraction and primer design}

Total RNA was extracted from the samples using the TransZol Up reagent (TransGen Biotech, Beijing, China). RNA integrity was assessed by $1.0 \%$ agarose gel electrophoresis. The $28 \mathrm{~S}, 18 \mathrm{~S}$, and 5S RNA were observed, and the band brightness ratio between 28S and 18S RNA was calculated as 2.0 (Figure 1). Ultraviolet-visible spectrophotometry (JY04s-3B, Beijing, China) (optical density [OD] at 260 and $280 \mathrm{~nm}$ ) was used to assess RNA quality and quantity, and the OD 260/280 ratios of the total RNA extract ranged between 1.9 and 2.1. The sequences, GenBank numbers and product lengths for each primer set are shown in Table 1. The primers were designed for exon-intron junctions using Primer 5.0 software or obtained from published literature.

Real-time polymerase chain reaction

Real-time PCR was conducted using the Applied Biosystems 7500 Real-time PCR System (Applied Biosystems, Carlsbad, CA, USA) and the SYBR Premix Ex Taq Kit (Takara, Dalian, China). The PCR mixtures contained $2 \mu \mathrm{L}$ of $\mathrm{cDNA}, 10 \mu \mathrm{L}$ of SYBR Premix Ex Taq, $0.4 \mu \mathrm{L}$ of PCR forward primer, $0.4 \mu \mathrm{L}$ of PCR reverse primer, $0.4 \mu \mathrm{L}$ of ROX Reference Dye II and $6.8 \mu \mathrm{L}$ of $\mathrm{dd}_{2} \mathrm{O}$. The real-time PCRs were performed at $95^{\circ} \mathrm{C}$

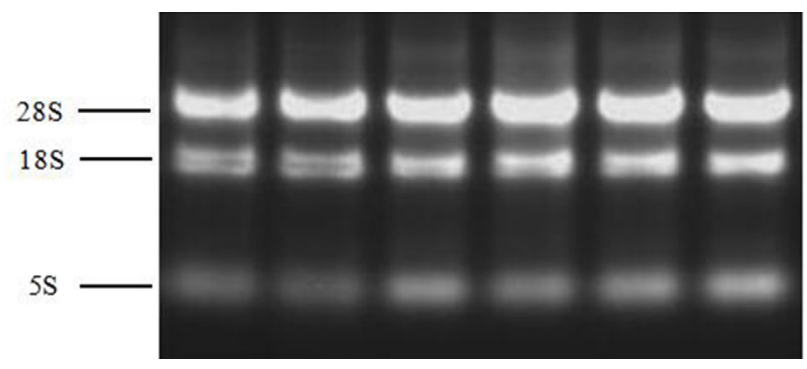

Figure 1. Agarose gel electrophoresis of the extracted total RNA. The 5S, 18S, and 285 RNA were observed, and the brightness ratio between 285 and 185 was calculated as 2.0. 
Table 1. Primers used for real-time polymerase chain reaction

\begin{tabular}{|c|c|c|c|}
\hline Gene & GenBank accession number & Primer sequence $\left(5^{\prime}-3^{\prime}\right)$ & Product size $(\mathrm{bp}) / \mathrm{Tm}\left({ }^{\circ} \mathrm{C}\right)$ \\
\hline GAPDH & NM_001082253.1 & $\begin{array}{l}\text { 5'-TCACCATCTTCCAGGAGCGA-3'; } \\
\text { 5'-CACAATGCCGAAGTGGTCGT-3' }\end{array}$ & $293 / 60$ \\
\hline$E G F$ & XM_008267485.1 & $\begin{array}{l}\text { 5'-AATGCCAACTGCACAAACAC -3 } \\
\text { 5'-CTGAAATGGCGGAACAGAAT -3 }\end{array}$ & $102 / 56$ \\
\hline$T G F \beta-1$ & NM_008249704.1 & $\begin{array}{l}\text { 5'-CCGTTTCTTTCGTGGGATAC-3 } \\
\text { 5'-GGTAAGGGAGGAGGGTCTCA-3 }\end{array}$ & $108 / 60$ \\
\hline$T G F \beta-2$ & NM_001082660.1 & $\begin{array}{l}\text { 5'-GAGAGGAGCGACGAGGAGTA -3 } \\
\text { 5'-TGAGCCAGAGGGTGTTGTAA -3 }\end{array}$ & $108 / 60$ \\
\hline$T G F \beta-3$ & NM_008272016.1 & $\begin{array}{l}\text { 5'-CACAACCCTCACCTCATCCT -3 } \\
\text { 5'-CCTGGCGGAAGTCAATGTAG -3 }\end{array}$ & $160 / 60$ \\
\hline$\beta$-Catenin & DQ786777.1 & $\begin{array}{l}\text { 5'-TTCTTGGGACTCTTGTTCAGC -3 } \\
\text { 5'-CACTTGGCACACCATCATCT -3 }\end{array}$ & $122 / 60$ \\
\hline
\end{tabular}

GAPDH, glyceraldehyde-3-phosphate dehydrogenase; IGF-I, insulin-like growth factor-l; EGF, epidermal growth factor; BMP2, bone morphogenetic protein 2; TGF $\beta$-1, transforming growth factor $\beta-1$; Wnt 10b, Wnt family member 10b.

for $10 \mathrm{~s}$ for pre-denaturation, followed by 40 cycles of denaturation at $95^{\circ} \mathrm{C}$ for $5 \mathrm{~s}$ and annealing and extension at $60^{\circ} \mathrm{C}$ for $40 \mathrm{~s}$. A standard curve was plotted to calculate the efficiency of the real-time PCR primers. Glyceraldehyde-3-phosphate dehydrogenase (GAPDH) was used as the housekeeping gene. Melting curve analysis was performed for all genes and showed that a single amplification product was produced by each reaction. No primer-dimers were generated during the PCR amplification cycles.

\section{Western blot analysis}

The Wnt $10 \mathrm{~b}$ and $\beta$-Catenin proteins were analyzed by western blotting. The frozen skin samples were ground with liquid nitrogen and then lysed in $500 \mu \mathrm{L}$ of precooled Radio Immunoprecipitation Assay buffer (Beyotime, Shanghai, China) with $1 \mathrm{mM}$ phenylmethanesulfonyl fluoride (Beyotime, China). The supernatant was collected after centrifugation at $12,000 \times \mathrm{g}$ for $10 \mathrm{~min}$ at $4^{\circ} \mathrm{C}$. The protein concentration was quantified with a BCA Assay Kit (Beyotime, China). An equal amount of protein $(40 \mu \mathrm{g})$ was separated by sodium dodecyl sulfate-polyacrylamide gel electrophoresis (SDS-PAGE) and transferred onto polyvinylidene fluoride membranes (Millipore, MA, USA). After blocking with triethanolamine-buffered saline containing 5\% fat-free milk powder (Beyotime, China) for $1 \mathrm{~h}$ at room temperature, the membranes were incubated at $4^{\circ} \mathrm{C}$ overnight with one of the following primary antibodies: anti$\beta$-catenin from Millipore (Cat.\#06-734, USA), anti-Wnt10b from Biorbyt (orb97574, USA), anti-GAPDH from Beyotime (AG019) or anti-Tubulin from Beyotime (AT819). Subsequently, the corresponding secondary antibody (IgG-conjugated horse- radish peroxidase) was added, and the samples were incubated for $4 \mathrm{~h}$ at $4^{\circ} \mathrm{C}$. After washing thrice with Tris-buffered saline containing Tween buffer for $10 \mathrm{~min}$, the signals were developed using an ECL system (Beyotime, China) and visualized by exposing the blots to X-RAY film (Kodak, Rochester, NY, USA). The films were then scanned (HP ScanJet 6100C, Hewlett Packard, Palo alto, CA, USA), and the signal intensity was calibrated by Image $1.43 \mathrm{~d}$ software (National Institutes of Health, Bethesda, MD, USA).

\section{Histological examination}

The skin samples were fixed with $4 \%$ paraformaldehyde and then dehydrated through a graded alcohol series, embedded in paraffin, sectioned at a thickness of $5 \mu \mathrm{m}$, and stained with hematoxylin and eosin. The HF development in skin was observed at 100× magnification by using a light microscope.

\section{Statistical analysis}

All data were analyzed using SAS software (SAS version 8e; SAS Institute, Cary. NC, USA). A one-way ANOVA model was used to evaluate the means among the various groups. $\mathrm{N}=$ 6 for all mRNA analyses. The data are shown as the means \pm standard error of the mean. Less than $0.05 \mathrm{p}$ value $(\mathrm{p}<0.05)$ was considered as statistically significant.

\section{RESULTS}

Morphological observation of hair follicle development We observed primary and secondary HF development in dorsal skin. The results showed that the HFs were mainly primary 
HFs at 0 weeks of age (Figure 2A). At 2 weeks old, the number of differential secondary HFs around the primary HFs reached 2 to 3 (Figure 2B). However, the number of differential secondary HFs around the secondary HFs did not increase, but the diameter of the primary HFs was obviously increased at 4 weeks old (Figure 2C). At 6 and 8 weeks old, the amounts of differential secondary HFs around the primary HFs obviously reached 5 to 13 (Figure 2D).

\section{Expression profiles of genes related to hair follicle development}

IGF-I transcripts were detected in skin samples collected from
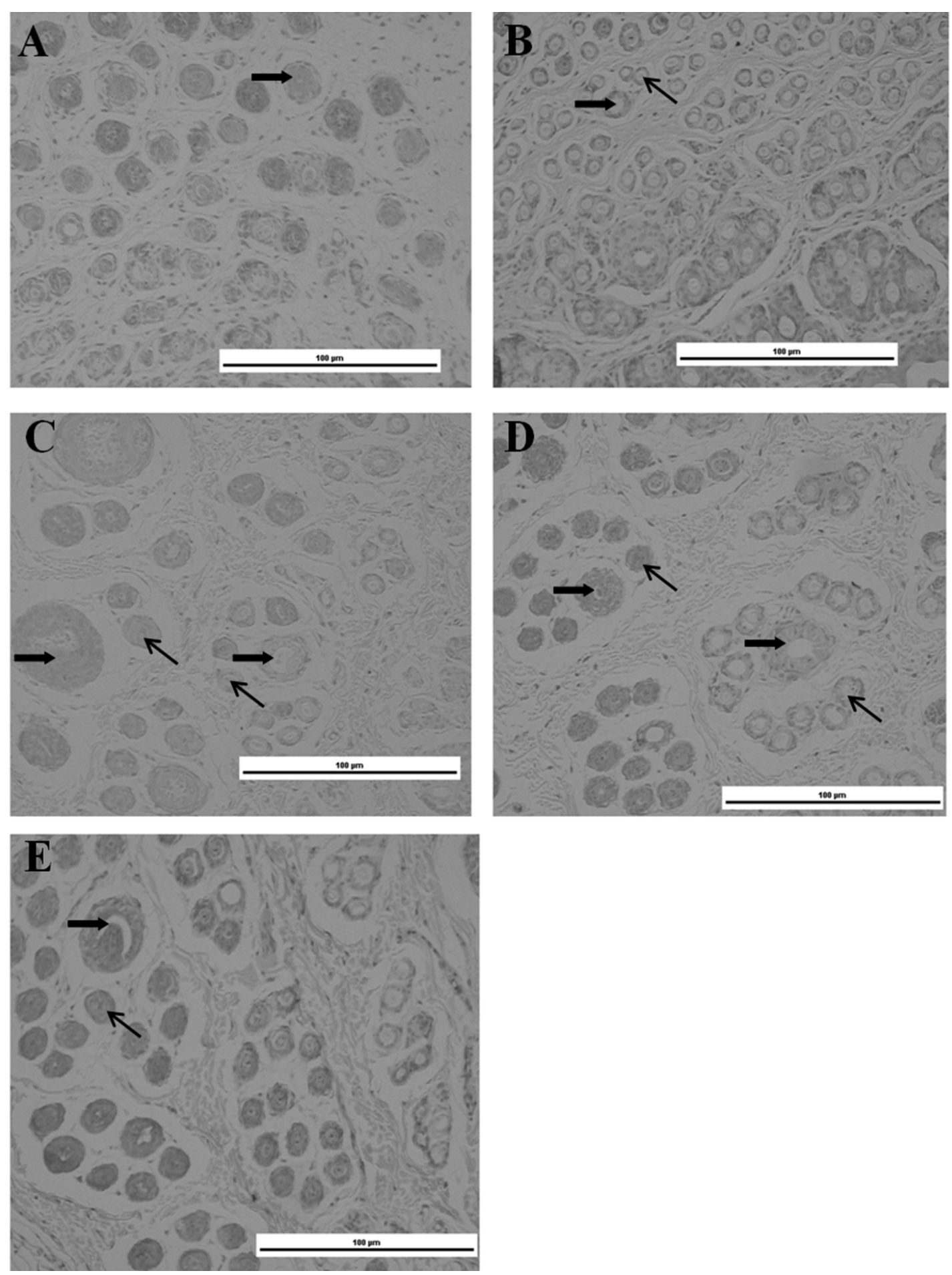

Figure 2. Structure of a vertical slip of skins from 0 to 8 weeks of age. (A) 0 weeks old. (B) 2 weeks old. (C) 4 weeks old. (D) 6 weeks old. (E) 8 weeks old. The skin was sectioned at a thickness of $5 \mu \mathrm{m}$ and then stained with hematoxyolin and eosin, magnification, $100 x ; \rightarrow$, the primary hair follicle (HF); $\rightarrow$, the secondary HF. 

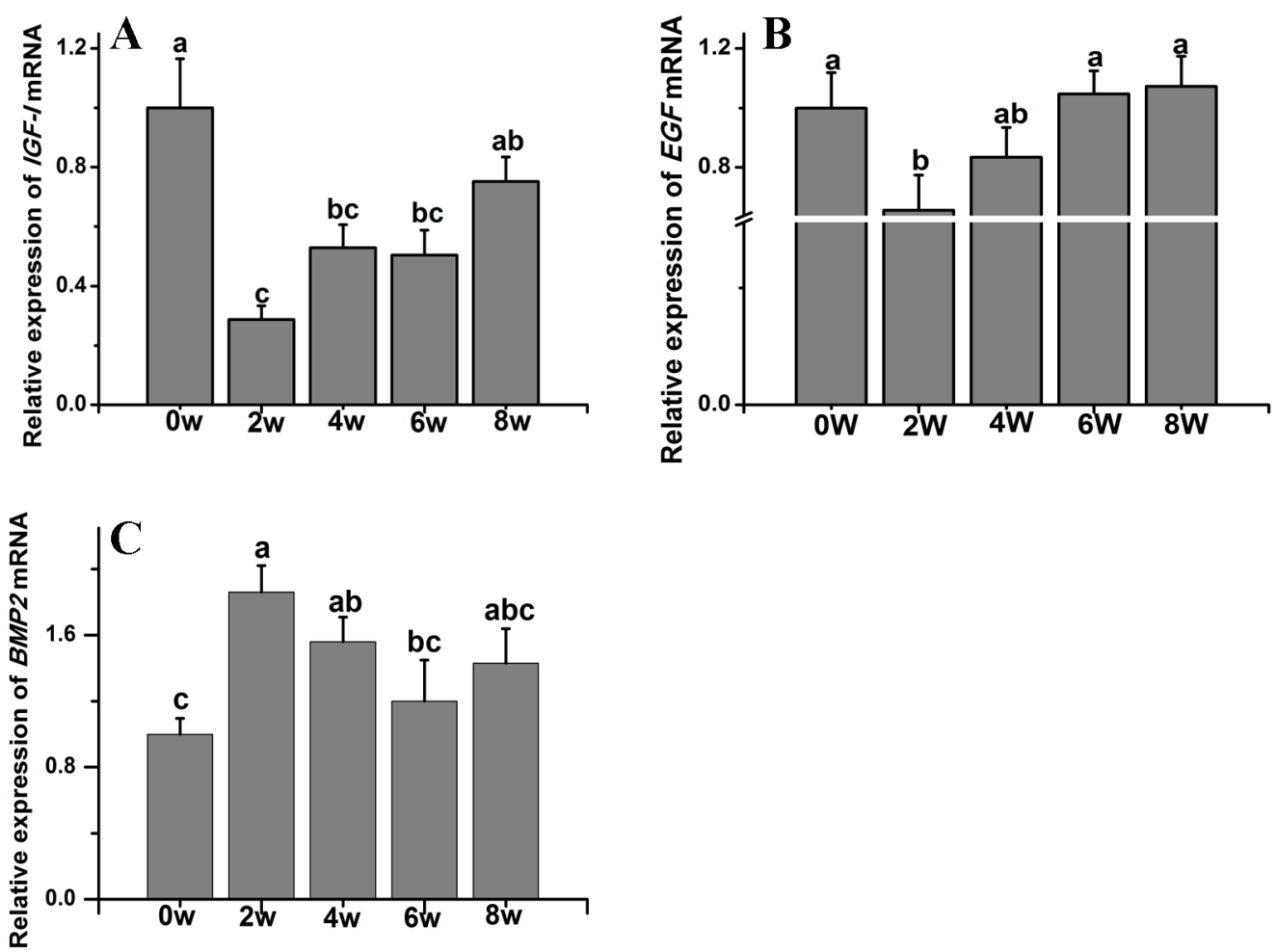

Figure 3. IGF-I, EGF, and BMP2 gene transcript levels in Rex rabbits from birth to 8 weeks old. (A) IGF-I transcript levels in Rex rabbits from birth to 8 weeks old. (B) $E G F$ transcript levels in Rex rabbits from birth to 8 weeks old. (C) BMP2 transcript levels in Rex rabbits from birth to 8 weeks old. w, weeks old; IGF-I, insulin-like growth l; EGF, epidermal growth factor; $B M P 2$, bone morphogenetic protein 2 . The data are presented as the means \pm stand error of mean, and $n=6$ for each group. ${ }^{a, b, c}$ Means with different superscripts differ $(p<0.05)$.

the backs of rabbits at all the tested time points (Figure 3A). The IGF-I transcript levels were significantly lower in animals at 2 weeks old than in those at birth $(\mathrm{p}<0.05)$. As the rabbits aged, IGF-I expression steadily increased until week 8.

The EGF transcript levels in rabbits at 2 weeks of age were significantly lower than those at 0,6 , and 8 weeks of age. No significant difference in $E G F$ transcript abundance was observed between weeks 2 and $4(\mathrm{p}<0.05)$ (Figure $3 \mathrm{~B})$.

Compared to those at week 0 , the BMP2 $(\mathrm{p}<0.05)$ (Figure 3C) and TGF $\beta-1(\mathrm{p}<0.05)$ (Figure $4 \mathrm{~A})$ transcript levels were significantly higher in 2-week-old animals and then gradually decreased thereafter. The TGF $\beta-2$ transcript levels were significantly lower at week 2 . The TGF $\beta-2$ transcript abundance was highest at week $8(\mathrm{p}<0.05)$ (Figure $4 \mathrm{~B})$. The TGF $\beta-3$ transcript levels were significantly lower at week 2 compared to those at weeks 0,6 , and 8 (Figure 4C).

$\beta$-Catenin gene expression was also significantly affected by age, while the $W n t 10 b$ transcript level was not affected in Rex rabbits during the first 8 weeks of postnatal life. The $\beta$-Catenin transcript levels were significantly increased compared to those at 0 weeks and peaked at 8 weeks old $(\mathrm{p}<0.05)$ (Figure 5).

The patterns of protein expression in dorsal skins The results showed that compared with the control group $(0$ weeks old), the ratio of $\beta$-Catenin protein expression in whole dorsal skin was significantly decreased at 2 and 4 weeks old and gradually increased thereafter $(\mathrm{p}<0.05)$ (Figure 6A). Additionally, the Wnt $10 \mathrm{~b}$ protein expression was also significantly

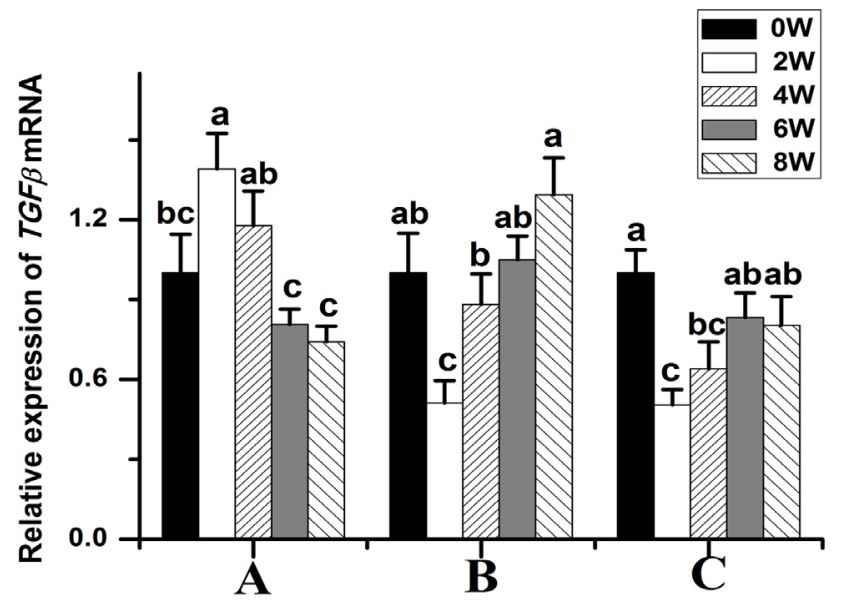

Figure 4. Transforming growth factor $\beta$ (TGF $\beta$ ) transcript levels in Rex rabbits from birth to 8 weeks old. (A) TGF $\beta$-1 transcript levels in Rex rabbits from birth to 8 weeks old. (B) TGF $\beta$-2 transcript levels in Rex rabbits from birth to 8 weeks old. (C) TGF $\beta$-3 transcript levels in Rex rabbits from birth to 8 weeks old. W, weeks old. The data are presented as the means \pm stand error of mean, and $n=6$ for each group. ${ }^{a, b, c}$ Means with different superscripts differ $(p<0.05)$. 

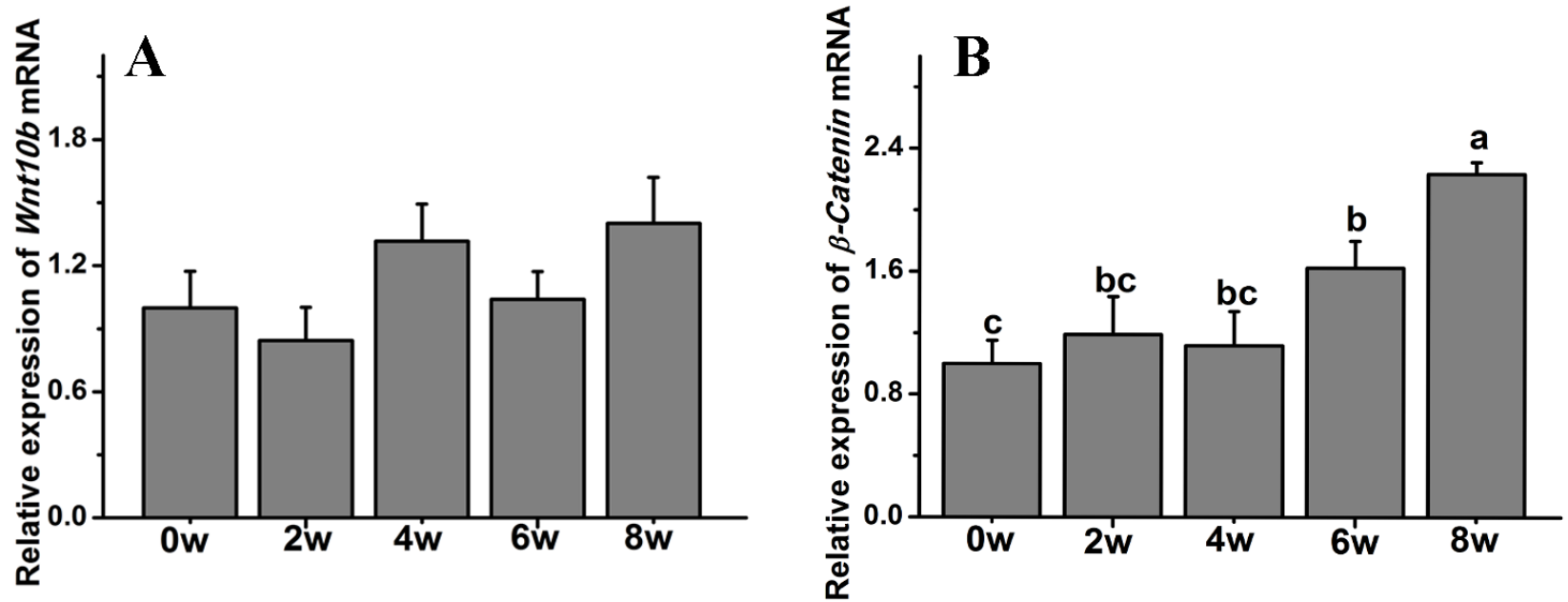

Figure 5. The gene transcript levels of Wnt10b and $\beta$-Catenin in Rex rabbits from birth to 8 weeks old. (A) Wnt10b transcript levels in Rex rabbits from birth to 8 weeks old. (B) $\beta$-Catenin transcript levels in Rex rabbits from birth to 8 weeks old. w, weeks old. The data are presented as the means \pm stand error of mean, and $n=6$ for each group. ${ }^{a, b, c}$ Means with different superscripts differ $(p<0.05)$.

decreased at 2 and 4 weeks old and then increased thereafter $(\mathrm{p}<0.05)$ (Figure 6b).

\section{DISCUSSION}

Skin growth and HF development are closely related, and many genes have been implicated in these processes. In the present study, we found that HFs have already formed in the back skin of rabbits at 0 weeks old, and genes such as IGF-I, EGF, BMP2, TGF $\beta-1, T G F \beta-2, T G F \beta-3$, Wnt 10b, and $\beta$-Catenin are all expressed in dorsal back skin at 0 weeks old. These results suggest that HF development is already underway at the embryo stage.

There are two distinct types of HFs in the skin of Rex rabbits: primary and secondary HFs [2]. During postnatal develop- ment, HFs show cyclic activity with periods of telogen, anagen and catagen expression [16,17]. Many genes, such as IGF-I, $E G F, B M P, T G F-\beta$, and $W n t$, have previously been identified as being important in this process. For example, IGF-I has a positive effect on the growth of cultured skin cells [6] and affects HF development [18]. The effect of EGF on HFs in epithelial tissue differs depending on the hair growth cycle stage [19]. $B M P$ signaling can inhibit HF regeneration via the maintenance of HFs in the telogen stage and the prevention of their activation by the advancing regenerative wave [20]. There are at least two distinct TGF- $\beta$ family pathways; one pathway is shared by $T G F \beta$, and the other is shared by the $B M P 2$ and $B M P 4$ subfamilies. Wht/ $\beta$-Catenin signaling is also required for the initiation and regeneration of HF development in mice
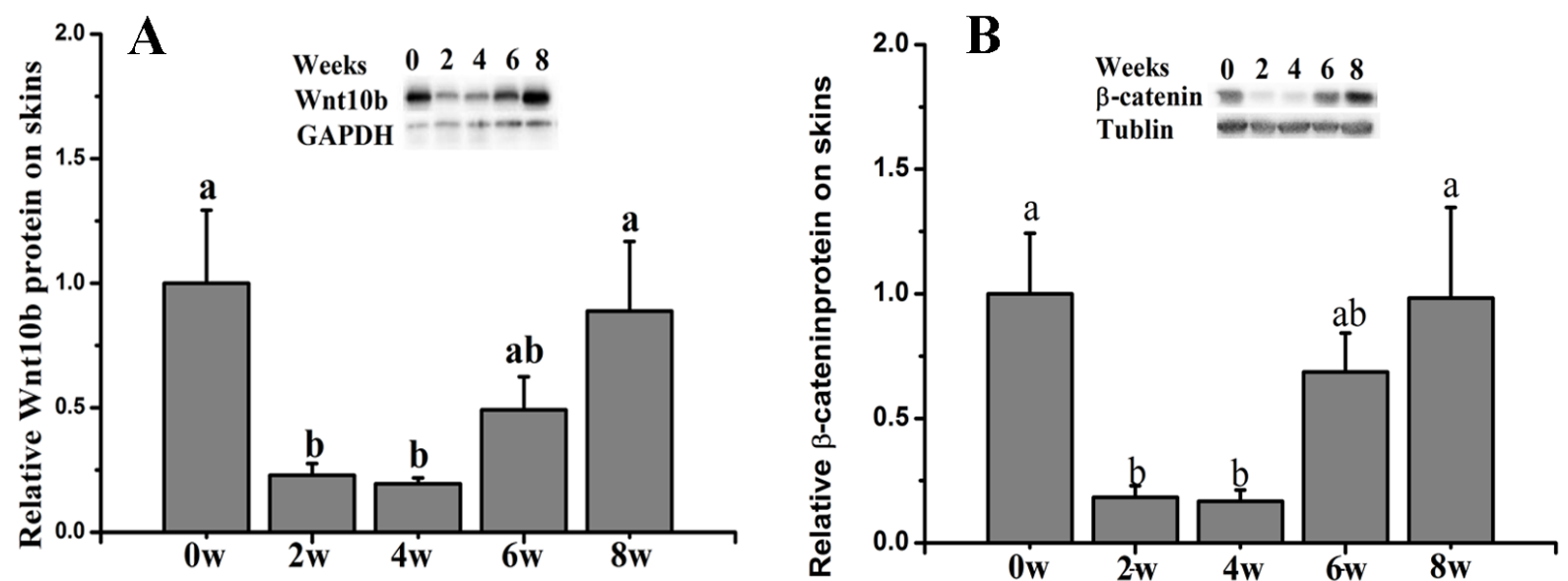

Figure 6. Relative levels of Wnt10b and $\beta$-Catenin protein expression in the skins of Rex rabbits from 0 to 8 weeks old. Skin extracts (50 $\mu \mathrm{g}$ protein/sample) were separated by $12 \%$ sodium dodecyl sulfate polyacrylamide gel electrophoresis for the determination of Wnt10b, $\beta$-Catenin, Tubulin, and GAPDH. The relative Wnt10b expression values were normalized to those of GAPDH, and the relative $\beta$-Catenin expression values were normalized to those of Tubulin. The data are presented as the means \pm stand error of mean. ${ }^{a, b}$ Means with different superscripts differ $(p<0.05)$, and $n=6$ for each group. 
[21]. In the present study, we detected a series of changes in the two types of HFs in Rex rabbits during the first 8 weeks of postnatal life. Moreover, the IGF-I, EGF, BMP2, TGF $\beta-1$, TGF $\beta$-2, TGF $\beta$-3, Wnt10b, and $\beta$-Catenin transcript levels were also significantly changed. These results suggested that the development of HF is closely related to the expression of these genes.

Hair development and the subsequent cycling follow a carefully choreographed rhythm, with cycling being controlled by multiple genes and pathways [22]. Among these pathways, $\mathrm{Wnt} / \beta$-Catenin signaling has been implicated in the development of skin and hair [11], and this pathway is required for the initiation of HF development [21]. In mice, Wnt10b was shown to promote HF growth in vitro and induce HF regeneration via the Wnt/ $\beta$-Catenin signaling pathway [23,24]. In the present study, we examined Wnt10b and $\beta$-Catenin protein and gene expression. The results showed similar Wnt10b and $\beta$-Catenin protein expression during HF development in dorsal skin. Both Wnt10b and $\beta$-Catenin were significantly decreased in 2 - and 4-week-old Rex rabbits. The results also suggested that $\mathrm{Wnt} / \beta$-Catenin signaling is involved in $\mathrm{HF}$ development. However, the transcript levels of Wnt10b and $\beta$-Catenin were inconsistent with their protein expression, suggesting that regulation may occur at the translational level. Indeed, a relationship between mRNA and protein expression more intrinsic and complex than a strictly linear relationship may exist [25].

\section{CONFLICT OF INTEREST}

We certify that there is no conflict of interest with any financial organization regarding the material discussed in the manuscript.

\section{ACKNOWLEDGMENTS}

The present study was financially supported by the Funds of Shandong "Double Tops" Program (grant number SYL2017 YSTD11) and the Earmarked Fund for Modern Agro-industry Technology Research Systems (CARS-43-B-1).

\section{REFERENCES}

1. Alonso L, Fuchs E. The hair cycle. J Cell Sci 2006;119:391-3.

2. Galbraith H. Fundamental hair follicle biology and fine fibre production in animals. Animal 2010;4:1490-509.

3. Zhu B, Xu T, Yuan J, Guo X, Liu D. Transcriptome sequencing reveals differences between primary and secondary hair folliclederived dermal papilla cells of the Cashmere goat (Capra hircus). PloS one 2013;8: e76282.

4. Moore GPM, Panaretto BA, Robertson D. Effects of epidermal growth factor on hair growth in the mouse. J Endocrinol 1981;
88:293-9.

5. Moore GPM, Panaretto BA, Robertson D. Epidermal growth factor delays the development of the epidermis and hair follicles of mice during growth of the first coat. Anat Rec 1983;205: 47-55.

6. Philpott MP, Sanders DA, Kealey T. Effects of insulin and insulin-like growth factors on cultured human hair follicles: IGF-I at physiologic concentrations is an important regulator of hair follicle growth in vitro. J Invest Dermatol 1994;102: 857-61.

7. Little JC, Westgate GE, Evans A, Granger SP. Cytokine gene expression in intact anagen rat hair follicles. J Invest Dermatol 1994;103:715-20.

8. Bierie B, Moses HL. Tumour microenvironment: TGF $\beta$ : The molecular Jekyll and Hyde of cancer. Nat Rev Cancer 2006;6: 506-20.

9. Massagué J. TGF $\beta$ in cancer. Cell 2008;134:215-30.

10. Lönn P, Morén A, Raja E, Dahl M, Moustakas A. Regulating the stability of TGF $\beta$ receptors and Smads. Cell Res 2009;19: 21-35.

11. Huelsken J, Vogel R, Erdmann B, et al. $\beta$-catenin controls hair follicle morphogenesis and stem cell differentiation in the skin. Cell 2001;105:533-45.

12. Ouji Y, Yoshikawa M, Moriya K, et al. Effects of Wnt-10b on hair shaft growth in hair follicle cultures. Biochem Biophys Res Commun 2007;359:516-22.

13. Ouji Y, Yoshikawa M, Moriya K, et al. Wnt-10b, uniquely among Wnts, promotes epithelial differentiation and shaft growth. Biochem Biophys Res Commun 2008;367:299-304.

14. Katoh M, Katoh M. WNT signaling pathway and stem cell signaling network. Clin Cancer Res 2007;13:4042-5.

15. De Blas C, Wiseman J. Nutrition of the rabbit. Oxfordshire, UK: CABI; 2010; 324 p.

16. Millar SE. Molecular mechanisms regulating hair follicle development. J Invest Dermatol 2002;118:216-25.

17. Botchkarev VA, Paus R. Molecular biology of hair morphogenesis: development and cycling. J Exp Zool Part B Mol Dev Evol 2003;298:164-80.

18. Rudman SM, Philpott MP, Thomas GA, Kealey T. The role of IGF-I in human skin and its appendages: morphogen as well as mitogen? J Invest Dermatol 1997;109:770-7.

19. Hansen LA, Alexander N, Hogan ME, et al. Genetically null mice reveal a central role for epidermal growth factor receptor in the differentiation of the hair follicle and normal hair development. Am J Pathol 1997;150:1959-75.

20. Plikus MV, Baker RE, Chen CC, et al. Self-organizing and stochastic behaviors during the regeneration of hair stem cells. Science 2011;332:586-9.

21. Andl T, Reddy ST, Gaddapara T, Millar SE. WNT signals are required for the initiation of hair follicle development. Dev Cell 2002;2:643-53.

22. Lei MX, Chuong CM, Widelitz RB. Tuning Wnt signals for 
more or fewer hairs. J Invest Dermatol 2013;133:7-9.

23. Li YH, Zhang K, Ye JX, et al. Wnt10b promotes growth of hair follicles via a canonical Wnt signalling pathway. Clin Exp Dermatol 2011;36:534-40.

24. Li YH, Zhang K, Yang K, et al. Adenovirus-mediated Wnt10b overexpression induces hair follicle regeneration. J Invest Dermatol 2013;133:42-8.

25. Strömberg S, Björklund MG, Asplund C, et al. A high-throughput strategy for protein profiling in cell microarrays using automated image analysis. Proteomics 2007;7:2142-50. 